\title{
Publisher Correction to: Comparative genetic analysis of grayling (Thymallus spp. Salmonidae) across the paleohydrologically dynamic river drainages of the Altai-Sayan mountain region
}

\author{
Steven Weiss • Jacqueline Grimm • Duarte V. Gonçalves • Giulia Secci-Petretto • \\ Gernot K. Englmaier • Mirgaliy Baimukanov $\cdot$ Elsa Froufe
}

Published online: 29 June 2020

(C) The Author(s) 2020

\section{Publisher Correction to:}

Hydrobiologia (2020) 847:2823-2844

https://doi.org/10.1007/s10750-020-04273-3

Due to an errror during the production process, the incorrect handling editor was displayed in the original publication. The handling editor mentioned in the original paper works at the same department as some of the authors, and he concluded that this might constitute a conflict of interest. The paper was therefore handled by one of the associate editors in chief. The correct footnote is published here and should be treated as definitive:

Handling editor: Diego Fontaneto

Publisher's Note Springer Nature remains neutral with regard to jurisdictional claims in published maps and institutional affiliations.

The original article can be found online at https:// doi.org/10.1007/s10750-020-04273-3.

S. Weiss $(\bowtie) \cdot$ J. Grimm · G. K. Englmaier Institute of Biology, University of Graz, Universitätsplatz 2, 8010 Graz, Austria

e-mail: steven.weiss@uni-graz.at

D. V. Gonçalves · G. Secci-Petretto · E. Froufe CIIMAR/CIMAR, Interdisciplinary Centre of Marine and Environmental Research, University of Porto, Terminal de Cruzeiros Do Porto de Leixões, Avenida General Norton de Matos, S/N, 4450-208 Matosinhos, Portugal

\section{G. Secci-Petretto}

Department of Biology, Faculty of Sciences, U. Porto University of Porto, Porto, Portugal

M. Baimukanov

Institute of Hydrobiology and Ecology, 75 Rakhmetov St, Irgely Village, Almaty, Kazakhstan 